\title{
Looking back
}

\section{Bray's discovery of pathogenic Esch. coli as a cause of infantile gastroenteritis}

\begin{abstract}
In the early 1940s at Hillingdon Hospital, Middlesex, Dr. John S. B. Bray discovered the role of pathogenic Esch. coli in infantile gastroenteritis and this work was published in 1945. When the old pathology laboratory at the hospital was converted for other use in 1968, Dr. Bray was invited to unveil a plaque commemorating his discovery in that laboratory (Fig. 1). His paediatric colleague, Dr. T. E. D. Beavan, and his chief technician, Mr. J. Stevenson, were also present (Fig. 2). At the time, Dr. Bray gave a vivid and fascinating account of his work, and the Editors of the Archives welcome the opportunity of making this available to the many who will take pleasure in reading it.

All who care for infants owe John Bray a special debt of gratitude, and the Archives of Disease in Childhood sends its greetings to him.
\end{abstract}

Perhaps you would like to know how the discovery was made. When I first came to Hillingdon Hospital from the Postgraduate Medical School as an Emergency Medical Service pathologist in 1939 at the start of the last war, one of my tasks was to perform necropsy examinations at the hospital. As a matter of fact, it was supposed at the time that there would be large numbers of bombing casualties. These fortunately did not materialize, but I soon found that there were very large numbers indeed of bottle-fed babies among my subjects. These children had died of gastroenteritis, or to give the disease two other names it went by-summer diarrhoea or cholera infantum. And cholera was a better name because, as in the tropical disease, many of the children apparently not in danger one minute were, in an hour or two more, in extremis.

This is not a reflection on the hospital at the time, because of course the causation of the disease and of its high infectivity was completely unknown, even though research into its causation had been done since the time of Pasteur and indeed also by Pasteur himself. It was a disease of theories and had devoted to it a whole chapter in the first edition of what was the bacteriologist's Bible, Topley and Wilson's Principles of Bacteriology and Immunity.

At all events, like many of my bacteriological predecessors, I became interested in the problem and $I$ began doing bacteriological work on these cases and, like everyone else, I got nowhere. The bacteriology was negative: all that was found was the normal Bacterium coli that appear on every culture plate of a faecal specimen. There were no dysentery bacilli, no salmonellae, no consistent findings of any significance, and indeed there was very little to be seen in the necropsy tissues. There was little from a pathologist's viewpoint to explain the death of these children. In fact, I was getting nowhere and this went on for about, I think, a year, in spite of the encouragement-even the importuning-of Dr. T. E. D. Beavan, our paediatrician.

One day something happened. Dr. Beavan came into the laboratory, as he very often did, and said, 'You know, I can spot these cases of gastroenteritis as soon as I go into the baby's cubicle'. I said, 'How do you do it ?' and he replied, 'They have a funny smell'. I said, 'What sort of a smell ?' and Dr. Beavan said, 'Well, they have a seminal smell'. I do not think that anything further was said at the time, but this was the clue I had been waiting for.

The first culture plate that I picked up from the laboratory bench from a case of gastroenteritis and which showed apparently normal flora, had a strong seminal smell-but one sniff and the smell had vanished. It was extremely evanescent, but it was there!

Well, from then on we started smelling our culture 
The upper storey of this building

was formerly the Pathology Laboratory

where, in collaboration with Dr. Thomas E.D.Beavan,

$$
\text { in } 1945 \text { Dr.JOHN S.B.BRAY }
$$

was the first to show convincing proof

of the major cause of severe Gastro-Enteritis in infants.

(2)

Fig. 1.-Commemorative plaque at Hillingdon Hospital. Uxbridge, unveiled in 1968.

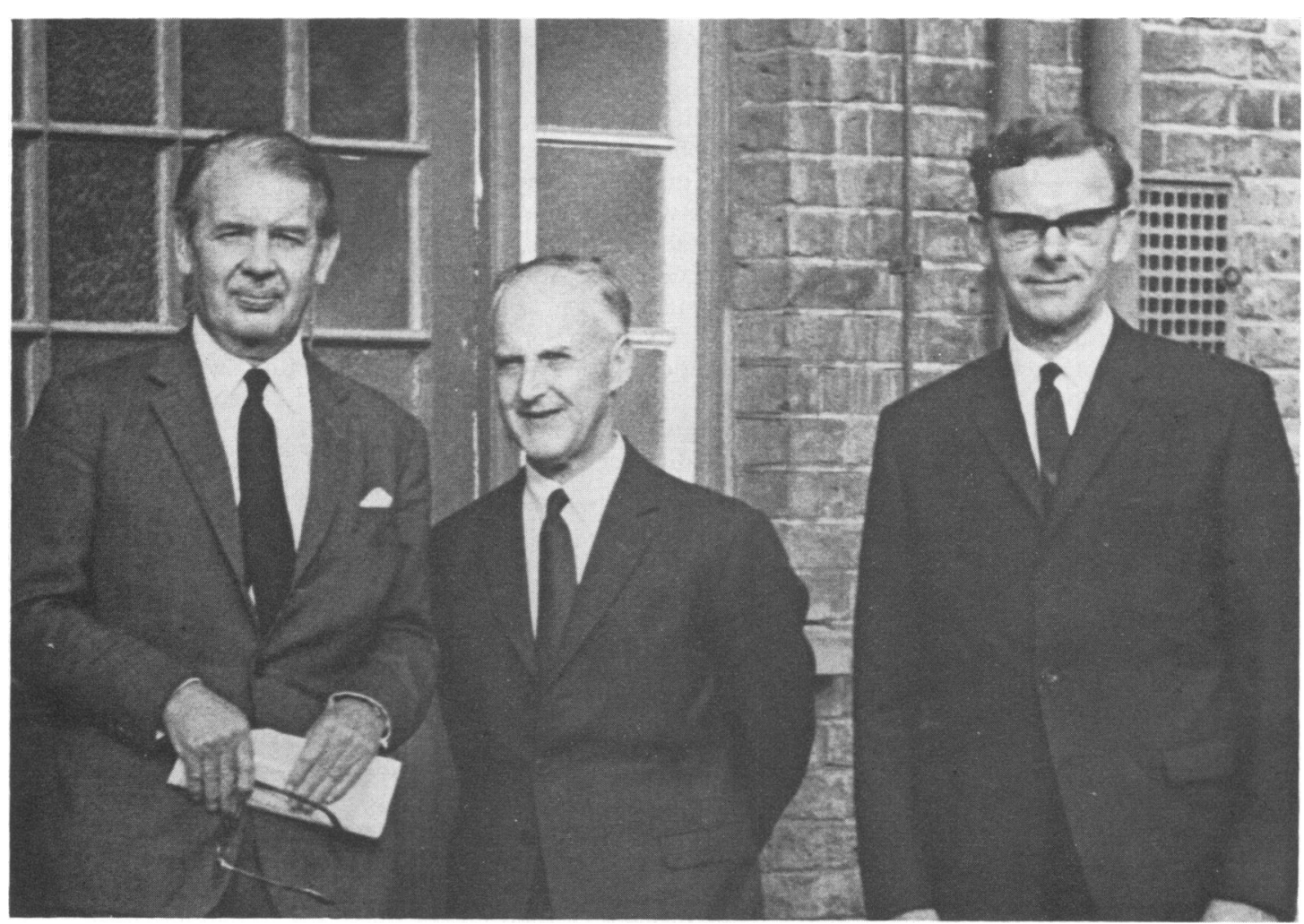

Fig. 2.-Dr. John Bray (left) with Dr. T. E. D. Beavan and Mr. J. Stevenson at the unveiling ceremony, Hillingdon Hospital, 1968. (Photo by E. Stride.) 
plates, Stevie and I-Mr. Stevenson, tireless, most friendly, and very expert technician from the Postgraduate Medical School, without whom this work could not have been done. We had rows of these culture plates on the laboratory bench which we used to sniff in turn and then mark as plus or minus. At about this time I took down to the children's wards two culture plates, one of Proteus, a common intestinal bacterium which has a strong smell, and one of the Bact. coli 'smellers', as we used to call them. I handed them to the ward sister, one after the other, and asked her to smell them. With the Proteus she said, 'Yes, a nasty smell, like glue,' but when she smelt the seminal smelling culture she exclaimed, 'Why, that smells just like Baby Wickens.'

I said, 'Sister, it is Wickens; it is the culture from Wickens.' It was at that moment that I knew the problem had been solved.

But of course you can't make a diagnosis on a smell, and an evanescent one at that. Something more than that was needed, something to give these suspicious but absolutely harmless looking germs an identity of their own.

One of the tests used for identifying intestinal bacteria is done by growing them in solutions of different sugars-glucose, maltose, lactose, and so on, and with the aid of a dye which changes colour, seeing which of them ferment these sugars and which do not. It so happened that, by chance, one night I left a rack of these tubes of the suspected bacteria on the laboratory bench and in the morning I noticed that, unlike normal Bact. coli, the suspects had slowly started to ferment maltose. The other suspicious cultures from cases of gastroenteritis did the same. This, then, was a second distinguishing feature besides the smell. They were late maltose fermenters.

But this was not much of a test either; still more was needed. It was necessary to make an antiserum and to determine whether these germs were antigenically homogeneous, in other words, whether they were chemically similar or whether they belonged to a hotchpotch of different types. We wanted to know whether the germs from the cases of gastroenteritis all reacted to the same antiserum and to prove that the germs got from normal children and adults did not so react.

At this time we had no rabbits at the hospital. All this research was being done on what has been called a 'string and plasticine' basis, but I did have some rabbits at my home near Windsor. One of these pet rabbits was called into service, a beautiful pure white one, I remember, most likely called Snowy, and he received an injection into his ear vein of the Wickens culture, this being quite some time after, I am sorry to say, this baby had died of his infection. From Snowy's blood an antiserum to the germ was made. I should say that this rabbit did not seem to mind about the procedure at all and, in fact, lived as a pet to a happy old age. The next step was to make a large collection of cultures from as many cases of gastroenteritis as possible, and another large collection of cultures of Bact. coli from normal children and adults-these cultures Stevie had to keep alive and look after-and then to see how the different cultures reacted with the rabbit antiserum; whether they agglutinated or not, and if they did agglutinate, to what extent.

This work took a long time; it was spread over a period of about four years and often the results were quite exasperating. The agglutination tests sometimes faiied to show the hoped for results, or else the supposed malefactors were found in apparently healthy children, or again were not isolated from cases thought by the clinicians to have the disease. On several occasions I felt with despair that I was deluding myself and was not on the right track at all; a feeling, I think, not rare in research of this kind. It must be remembered again that cultures of these germs looked like perfectly normal intestinal bacteria growing as pink colonies on the MacConkey plate, and not as the white colonies such as dangerous salmonellae would produce. This, of course, was the reason why these germs, equally dangerous for infants, had gone undetected for so long. Generations of medical bacteriologists had been trained to look on these pink, lactosefermenting colonies grown from faecal specimens as harmless. They always discarded such cultures and wrote 'Normal flora' in their reports. So you will see I had some reason to fear that I might be in for a disappointment.

However, in the end, all these setbacks were to be explained. The apparently normal children who had the germ turned out either to have had the disease earlier in a mild form and had recovered, or else later they actually came down with the disease and became moderately or severely ill. The cases where the germ was not found were only suffering from uninfectious digestive disturbances which had been mistakenly diagnosed. I believe that my statistics showed finally that some $95 \%$ of severe cases of gastroenteritis at that period were infected with the 'smeller' organism.

Several other investigations were carried out at this time. For example, it had long been known that gastroenteritis was associated with a rise in the fly population during hot weather-hence the name, summer diarrhoea. I used to catch house flies 
flying around the hospital. These I squashed and cultured, and in two of these flies I found the suspect organism. Here was clearly one way in which the germ could be transmitted, though it is now known that there are many other ways in which it can be spread, and indeed during an epidemic it becomes widely distributed.

Another investigation was to attempt to give the disease to baby mice, rabbits, and kittens by feeding them with the appropriate cultures. To my surprise all these attempts resulted in complete failure. The germ, if it caused the disease, was apparently specific for young humans. The third of Koch's postulates was thus not fulfilled. Obviously, one could not prove the case by trying the effect of feeding the germ to a healthy baby, though years later diarrhoea was produced in America in adult volunteers in this way.

Another attempt was made to try and relate the disease to white scours, a diarrhoea afflicting newborn calves. My germs did not agglutinate with any of the sera I got from the veterinary laboratories which had been made against Bact. coli strains isolated from calves. This meant that the calf strains were unrelated to the human strains.

The final step, having at last found my antiserum by great good fortune to react consistently with the organisms of human origin from undoubted cases of the disease, was to devise a simple test which was, if I am allowed to say so, a real triumph in the control of this fatal illness. The test was a means of quickly distinguishing these cases of cholera infantum from the cases which were simply digestive upsets. For the first time the physician was able to isolate or segregate these very infectious cases from the healthy children, or more exactly those who were in hospital for some other reason.

All this was done by picking one colony from a MacConkey culture plate-I emphasize one colony because in the gastroenteritis cases the entire bacterial flora consisted solely of the 'smellers'-and then by rubbing this colony up with some of my serum on a glass slide. When the slide was rocked in the manner one was accustomed to use in a blood grouping test, at once in the infected cases there was a marked agglutination. A diagnosis in $\mathbf{1 2}$ hours.

Perhaps better methods are used today, but at the time this was something quite new.
Eventually, these results were first published in the Journal of Pathology and Bacteriology in 1945, and I regret to say that no one, with the exception of the editor of the journal, believed that my findings were of any importance whatever. I remember him coming up to me at one of the meetings of the Society of Pathology and Bacteriology at Oxford, saying, 'I'm sure that you've found the answer, but we can't say so.'

However, Stewart of Glasgow, and Giles and Sangster of Aberdeen, and Smith of Aberdeen all confirmed my observations. I must mention, too, Dr. ten Seldam of Eindhoven, now Professor of Pathology at Perth University, Western Australia, who had got similar results in Holland, who came to see me in London, and who was kind enough to name the organism 'Escherichia coli bray'. All these people and many others began to isolate the germ from their cases of gastroenteritis, and gradually the weight of evidence accumulated. As the results in the different laboratories throughout the world, even as far away as Japan, began to be reported, all were found confirmatory of the Hillingdon findings.

By now the organism was having its antigenic structure examined more closely, and it had been renamed Escherichia coli O111·B4. Several other strains of Esch. coli of varying pathogenicity associated with gastroenteritis had turned up in different epidemics and had been given numbers corresponding to their antigenic structure.

The original $\mathrm{O} 111 \cdot \mathrm{B} 4 \mathrm{Wickens}$ strain is still with us. It has not died out, but retains its orginal power to cause infantile gastroenteritis. But the days when thousands of children in the United Kingdom died each year from the disease have departed.

\section{REFERENCES}

Beavan, T. E. D. (1944). In discussion on infantile gastroenteritis. Lancet, 1, 568.

Bray, J. (1945). Isolation of antigenically homogeneous strains of Bact. coli neapolitanum from summer diarrhoea of infants. Fournal of Pathology and Bacteriology, 57, 239.

Bray, J., and Beavan, T. E. D. (1948). Slide agglutination of Bacterium coli var. neapolitanum in summer diarrhoea. fournal of Pathology and Bacteriology, 60, 395.

Correspondence to Dr. H. V. L. Finlay, Department of Paediatrics, Hillingdon Hospital, Uxbridge, Middlesex. 